\title{
Stand Up of Uranium Capability for Swipe Analysis
}

\author{
Matthew Watrous \\ Anthony Appelhans \\ Robert Hague \\ Tracy Houghton \\ John Olson
}

November 2013

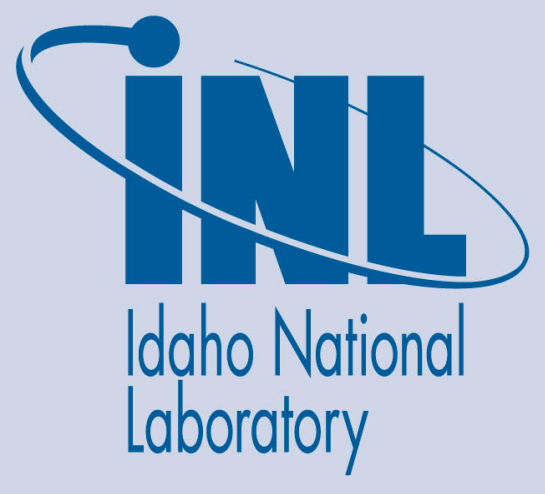

The INL is a U.S. Department of Energy National Laboratory operated by Battelle Energy Alliance 
INL/EXT-13-30689

\title{
Stand Up of Uranium Capability for Swipe Analysis
}

\author{
Matthew Watrous \\ Anthony Appelhans \\ Robert Hague \\ Tracy Houghton \\ John Olson
}

November 2013

\section{Idaho National Laboratory \\ Idaho Falls, Idaho 83415}

http://www.inl.gov

Prepared for the

U.S. Department of Defense

and for the

U.S. Department of Energy

Under DOE Idaho Operations Office

Contract DE-AC07-05ID14517 


\section{Introduction}

The INL has established the capability to process and analyze swipe samples to determine if the amount of $\mathrm{U}$ and $\mathrm{Pu}$ present on equipment and facilities are at the level typical for natural background, to quantify their isotopic composition and to determine if any off-normal isotopic ratio present in the sample is statistically relevant. A previous report detailed this capability for $\mathrm{Pu}$ and preliminarily for $\mathrm{U}$; this report describes the measurements and analysis that were performed to demonstrate the INL capability for U.

To establish that a piece of equipment is not contaminated with the element to be sampled, a fabric swipe is used to collect a sample of the materials present on the surface. The swipes are then processed and analyzed to determine if $\mathrm{Pu}$ and $\mathrm{U}$ are present on the sample at levels above what is accepted as natural background and, for the case of $U$, whether the isotope ratios deviate from the accepted natural background levels. Both the method applied for chemical processing of the swipes to remove and isolate the $\mathrm{U}$ and $\mathrm{Pu}$ and the method used to analyze the extracts influences the sensitivity and specificity. Over the years various methods have been developed for processing and analyzing these types of samples; the gold standard for these measurements involves a lengthy and complex separation process followed by analysis using thermal ionization mass spectrometry (TIMS). However, this method is expensive and time consuming, thus driving a need for a less complicated and more efficient method that provides the necessary level of sensitivity and specificity.

Advances in Inductively Coupled Plasma Mass Spectrometry (ICPMS) over the last decade have enabled analyses of $U$ and $\mathrm{Pu}$ that rival that of TIMS. This, coupled with the potential for simplifying the extraction and separation process required for an ICPMS analysis, prompted the INL's development of methods that provide the analysis of swipes in a timely and efficient manner.

$\mathrm{U}$ is present in the blank swipe material at nanogram $\left(\sim 2 \times 10^{-9} \mathrm{~g}\right)$ levels for a typical sample, a level easily detected with ICPMS. The abundance of the isotopes ranges over 4 orders of magnitude for the naturally occurring ${ }^{234} \mathrm{U},{ }^{235} \mathrm{U}$ and ${ }^{238} \mathrm{U}$ and a goal was set to be able to detect the presence of ${ }^{236} \mathrm{U}$ at 6 orders of magnitude lower than the ${ }^{238} \mathrm{U}$. The ${ }^{236} \mathrm{U}$ measurement is particularly important because the presence of ${ }^{236} \mathrm{U}$ is a strong indicator that the uranium as been in a nuclear reactor. To demonstrate these capabilities the following sample types were used: blank swipe material, blank process reagents, swipe material spiked with a natural abundance U isotope standard, swipe material spiked with an environmental standard (Columbia River sediment), and swipes taken at various locations within the processing laboratories and the INL environment.

This report summarizes the method used to extract the $U$ from the swipe material, the ICPMS analyses that demonstrate the limit of detection (LOD) and the limit of quantification (LOQ) for the $\mathrm{U}$ isotopes of interest, the precision of the measured isotope ratios and the dependence of precision on the quantity of $U$ present, and the method proposed to determine if an off-normal ratio is statistically relevant. 


\section{Sample Preparation and Processing}

The methods discussed in this report were developed to analyze environmental samples collected on a commercial swipe material. As uranium is ubiquitous in the environment it is typically found in the materials and reagents used to collect and process the samples. Thus any measurement of uranium must account for the possible influence of this background on quantification and on the various isotope ratios. For these studies background levels of uranium and the associated ratios were measured for samples of the blank swipe material and the reagents.

To measure the quantity (mass) of each of the target isotopes in the samples a spike of

${ }^{233} \mathrm{U}$ (CRM 111-A, New Brunswick Laboratory) was added to each sample before processing. Serial dilutions of the standard were performed and tracked by weight to produce the concentration needed for spiking individual samples with $3.3 \mathrm{pg}$ of ${ }^{233} \mathrm{U}$.

Three categories of samples were produced and analyzed: swipe material with a natural uranium standard (CRM 145, New Brunswick Laboratory, see Appendix A) applied prior to processing, swipe material with a sediment standard (CRM 4350B, NIST) with a nonnatural uranium isotopic composition applied prior to processing, and samples generated by swiping a variety of surfaces within the processing laboratory and the general INL environment.

Sample processing took place in clean rooms located in the IRC-611 building located at the INL Research Center (IRC) in Idaho Falls. Sample analysis was conducted in a standard laboratory located in the IRC-603 building which is $\sim 500$ yards from IRC-611. The samples were transferred from the clean room to the analysis laboratory in sealed vials.

The samples were initially dry-ashed in a muffle furnace followed by a wet-ash performed in a Teflon beaker using nitric, hydrofluoric and perchloric acids. Chemistry methods, developed by Eichrom, using commercially available UTEVA and TRU columns were used to separate the $\mathrm{Pu}$ and $\mathrm{U}$ fractions. The sample was passed through a UTEVA column which has an affinity for uranium but not plutonium (the TRU column was staged below the UTEVA column to collect the Pu fraction). The UTEVA cartridge was rinsed and the uranium eluted from the column to produce the samples for the ICPMS.

\section{ICPMS Analysis Method and Data Processing}

A Neptune Plus ICPMS was used for all sample analysis. The instrument is configured with both Faraday cups and ion counting detectors that enable simultaneous detection of the $U$ isotopes of interest; it has been described in detail elsewhere. The samples were diluted to a level where the ${ }^{235} \mathrm{U}$ and ${ }^{238} \mathrm{U}$ were detected with a faraday cup and the ${ }^{233} \mathrm{U}$, ${ }^{234} \mathrm{U}$, and ${ }^{236} \mathrm{U}$ masses were detected with ion counting detectors. A cross calibration of each ion counter to the faraday cup used to measure the ${ }^{238} \mathrm{U}$ was performed at the beginning of each day. Dead time corrections and dark noise corrections were quantified and the instrument was tuned for optimum response each day. A blank was run every other sample and standards were injected to bracket every three samples. A blank swipe 
that was processed with the sample set was run at the beginning of a sample sequence and at the end. All data was collected and processed with the Neptune Plus software.

The data was corrected for detector cross calibration and blank subtracted. The blank subtraction was performed by using the average of the blank injection just before and just after each sample run. Mass bias was corrected using the CRM145 standard injected to bracket every three samples. The following equations were used to calculate the mass bias correction:

\section{Equation 1}

$$
K_{A / B}=\left(\frac{\operatorname{mass} A}{\operatorname{mass} B}\right)^{\beta}
$$

$K_{A / B}=$ mass bias correction for the isotopes of mass A and mass B

mass $A={ }^{234} \mathrm{U}$ as an example

mass $B={ }^{238} \mathrm{U}$ as an example

$\beta=$ defined by the equation 2 below

Equation 2

$$
\beta=\frac{\ln \left(\left(\frac{A}{B}\right)_{\text {std }} /\left(\frac{A}{B}\right)_{\text {meas }}\right)}{\ln (\text { mass } A / \text { mass } B)}
$$

$(A / B)_{\text {std }}=\left({ }^{234} \mathrm{U} /{ }^{238} \mathrm{U}\right)_{\text {std }}=$ certificate value of the ${ }^{234} \mathrm{U} /{ }^{238} \mathrm{U}$ ratio as an example. $(A / B)_{\text {meas }}=\left({ }^{234} \mathrm{U} /{ }^{238} \mathrm{U}\right)_{\text {meas }}=$ measured value of the ${ }^{234} \mathrm{U} /{ }^{238} \mathrm{U}$ ratio as an example.

$\beta$ is calculated using the average of the ${ }^{234} \mathrm{U} /{ }^{238} \mathrm{U}$ ratios of the bracketing CRM 145 standards, and substituted in the first equation to calculate the mass bias correction for each of the other ratios.

A goal in the development of these methods was to be able to detect ${ }^{236} \mathrm{U}$ at a level 6 orders of magnitude below that of the ${ }^{238} \mathrm{U}$. Two corrections were needed to determine the proportion of the signal at mass 236 that is attributable to ${ }^{236} \mathrm{U}$ : correction for ${ }^{235} \mathrm{U}^{1} \mathrm{H}$ and correction for baseline tailing of the 235 and 238 signals. The hydride ratio was estimated using the ratio of the 239 mass signal to the 238 mass signal of a blank processed swipe run on the ICPMS at the beginning and the end of the sample set. This makes the assumption that the 239 mass signal did not include any contribution from

${ }^{239} \mathrm{Pu}$, an assumption verified by noting that signals of other $\mathrm{Pu}$ isotopes were not detected. The estimated hydride contribution from the ${ }^{235} \mathrm{U}^{1} \mathrm{H}$ was subtracted from the gross 236 signal. The baseline correction to account for tailing from the mass 238 and mass 235 signals into the mass 236 signal was calculated using the average of the signals at mass 235.5 and 236.5. Mass 233, 234, 235 and 238 signals are used as measured with no hydride or tailing corrections. 


\section{Results}

The measurements from the standards, blank swipes, the process reagents, and the three categories of samples are reported in this section.

\section{CRM 145 Standard}

Figures 1 and 2 present the measured isotope ratios of the CRM 145 standard. The results demonstrate that the method produces an accurate measurement of both the ${ }^{235} \mathrm{U} /{ }^{238} \mathrm{U}$ and ${ }^{234} \mathrm{U} /{ }^{238} \mathrm{U}$ ratio. The 2 sigma uncertainty is $\sim 0.4 \%$ for the ${ }^{235} \mathrm{U} /{ }^{238} \mathrm{U}$ ratio and $6 \%$ for the ${ }^{234} \mathrm{U} /{ }^{238} \mathrm{U}$ ratio. The measured limit of detection for ${ }^{238} \mathrm{U}$ from the CRM 145 spiked onto a swipe is $7.1 \times 10^{11}$ atoms of ${ }^{238} \mathrm{U}(0.28 \mathrm{ng})$ with the limit of quantification being $2.4 \times 10^{12}$ atoms of ${ }^{238} \mathrm{U}(0.93 \mathrm{ng})$. The uncertainty for all of the measurements is a function of the mass of uranium in the sample. Figure 3 illustrates the dependence of the 1 sigma uncertainty on the mass of uranium in the sample.

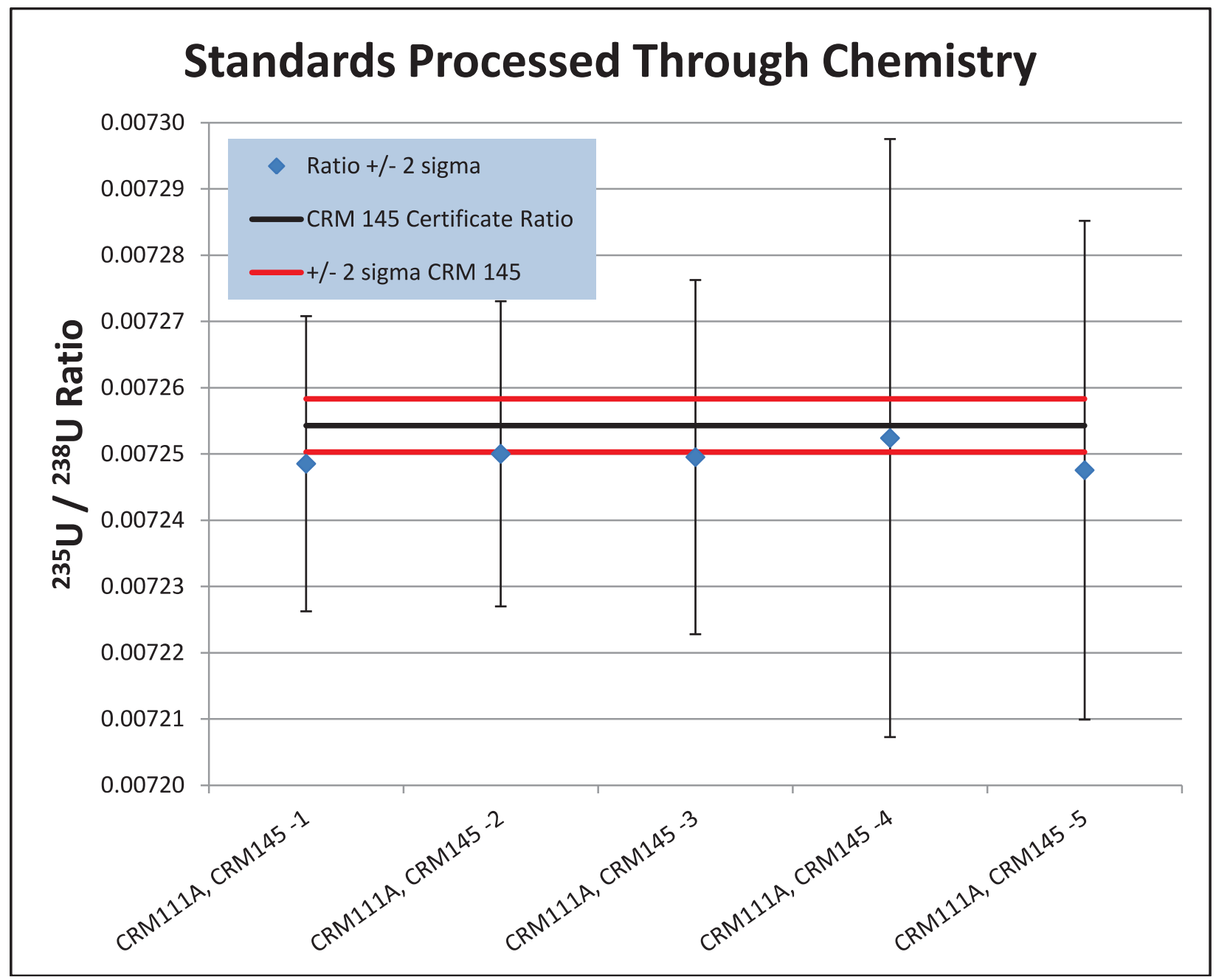

Figure 1. Measured ${ }^{235} \mathrm{U} /{ }^{238} \mathrm{U}$ ratios of standards CRM 111A (3.3 fg) and NBS CRM 145 (22 ng) processed through the chemistry. Data show +/- 2 sigma with the natural standard CRM 145 certified value shown on the bold black line and the uncertainty at 2 sigma is plotted in red. 


\section{Standards Processed Through Chemistry}

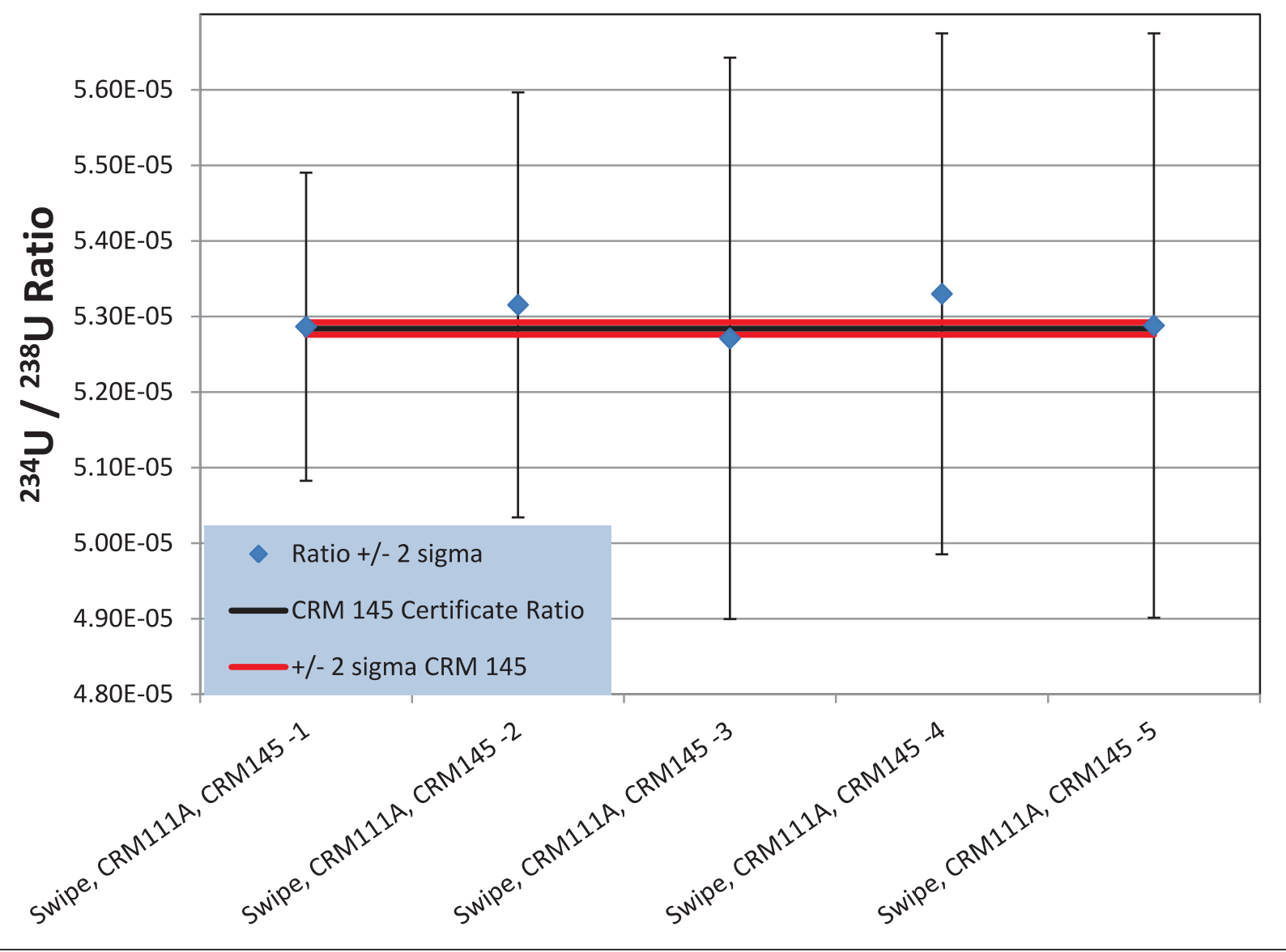

Figure 2. Measured ${ }^{234} \mathrm{U} /{ }^{238} \mathrm{U}$ ratios of standards CRM 111A (3.3 pg) and NBS CRM 145 (22 ng) processed through the chemistry. Data show +/- 2 sigma with the natural standard CRM 145 certified value shown on the bold black line and the uncertainty at 2 sigma is plotted in red. 


\section{Uncertainty vs Amount of Uranium on Swipe}

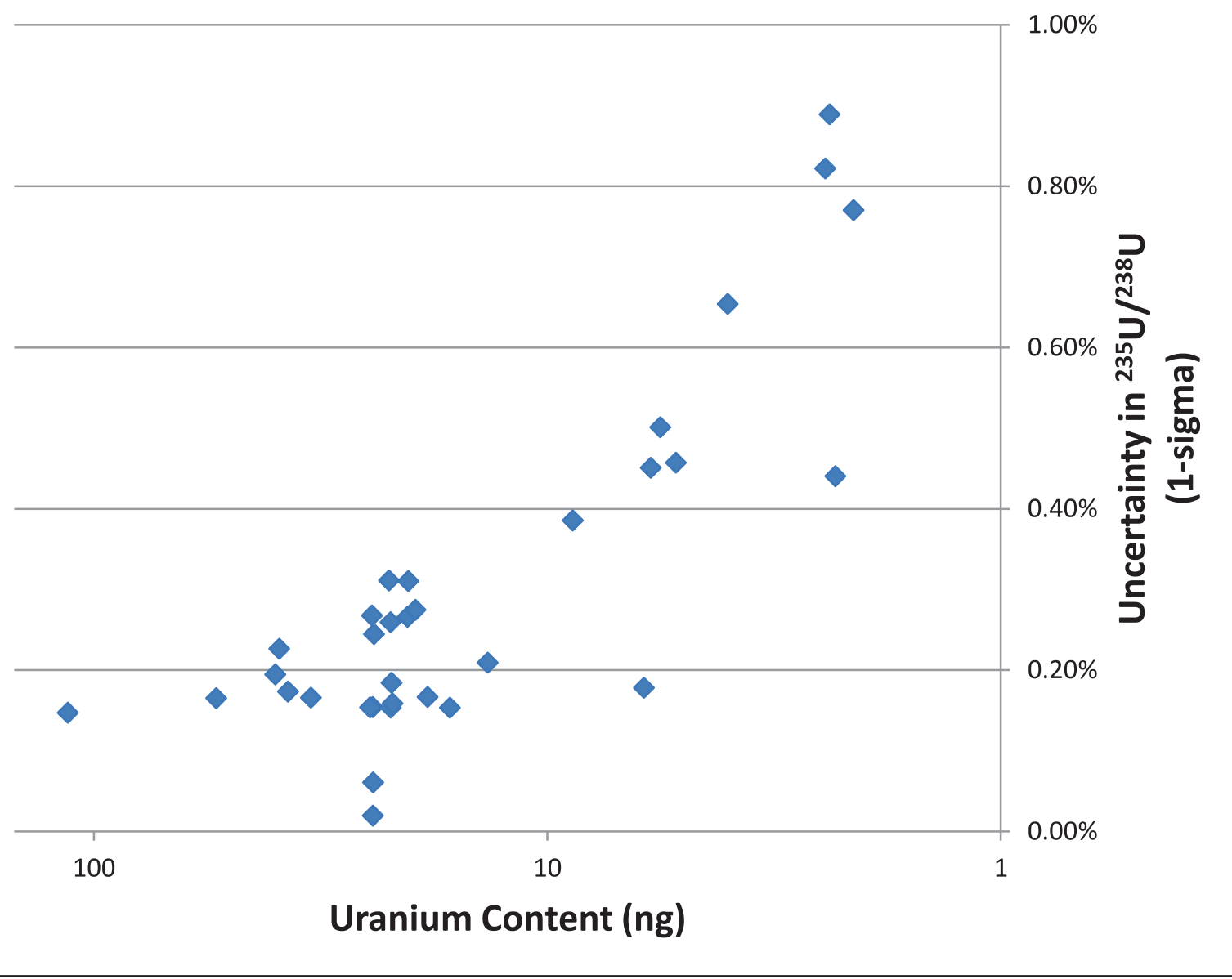

Figure 3. Plotting uranium mass on the $x$-axis and uncertainty expressed as a percentage on the $y$ axis. Larger quantities of uranium lead to smaller uncertainty. As the quantity of uranium decreases, the magnitude of the uncertainty increases.

\section{Blank Swipes}

Figures 4 and 5 present the measured isotope ratios for ${ }^{235} \mathrm{U} /{ }^{238} \mathrm{U}$ and ${ }^{234} \mathrm{U} /{ }^{238} \mathrm{U}$ from blank sample swipes. The measured ${ }^{235} \mathrm{U} /{ }^{238} \mathrm{U}$ ratio, within the uncertainty bands, corresponds to natural abundance. The ${ }^{234} \mathrm{U} /{ }^{238} \mathrm{U}$ ratio is enriched in ${ }^{234} \mathrm{U}$ relative to natural; it is not uncommon to see this level of variation in uranium isotope ratios due to the inhomogeneous distribution of uranium in the environment. It would also not be unreasonable to expect that this ratio may differ from batch to batch of the swipe material; thus it should be quantified for each distinct batch. The amount of uranium in a blank swipe is about $2.5 \mathrm{ng}$, which for a typical swipe of an environmental sample would represent only about $10 \%$ of the total sample. ${ }^{236} \mathrm{U}$ was not detected in these samples. 


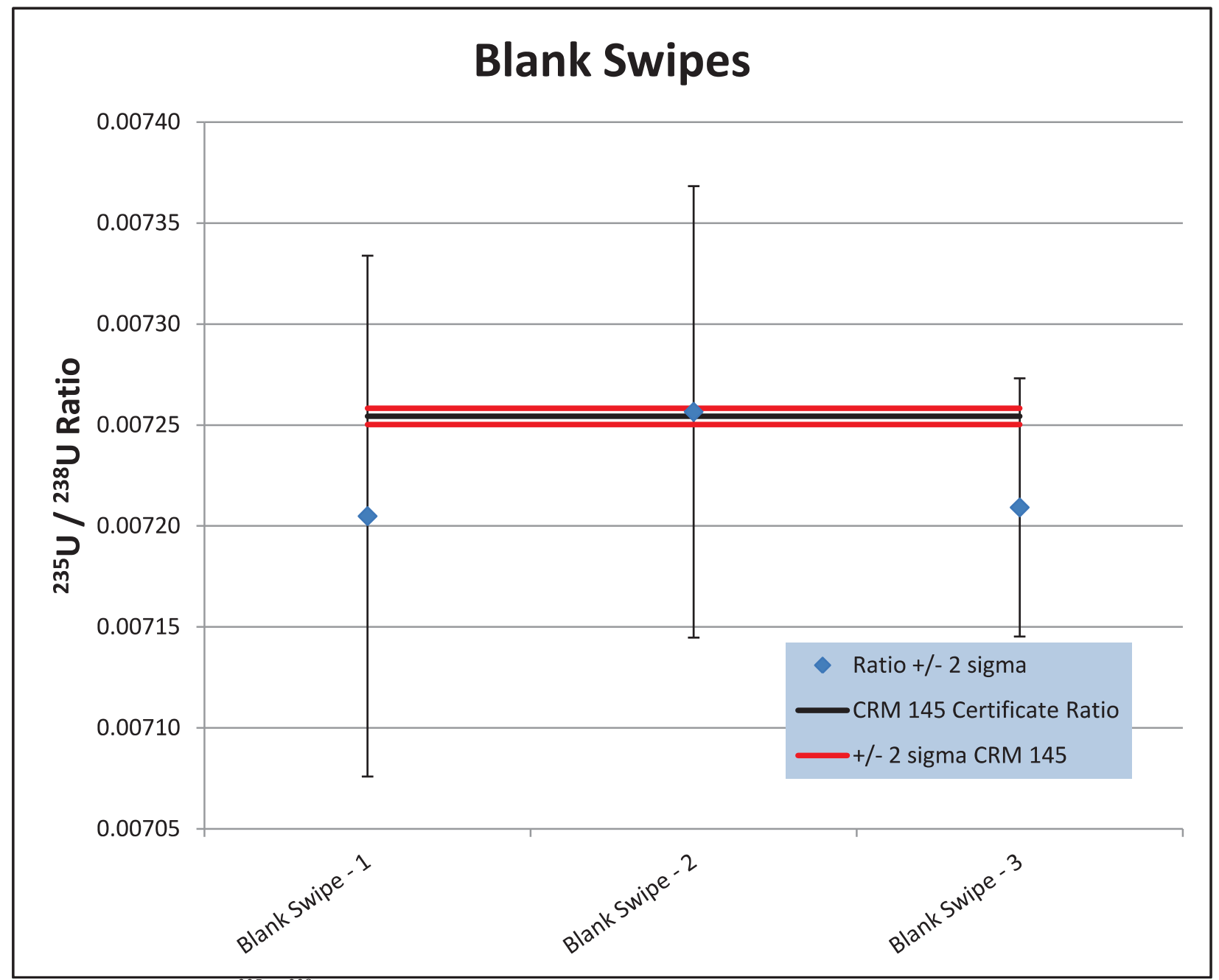

Figure 4. Measured ${ }^{235} \mathrm{U} /{ }^{238} \mathrm{U}$ ratios of clean swipes processed through the chemistry along with 3.3 pg of CRM 111A for quantification and measured by ICPMS. Data show +/- 2 sigma with the natural standard CRM 145 certified value shown on the bold black line and the uncertainty at 2 sigma is plotted in red. 


\section{Blank Swipes}

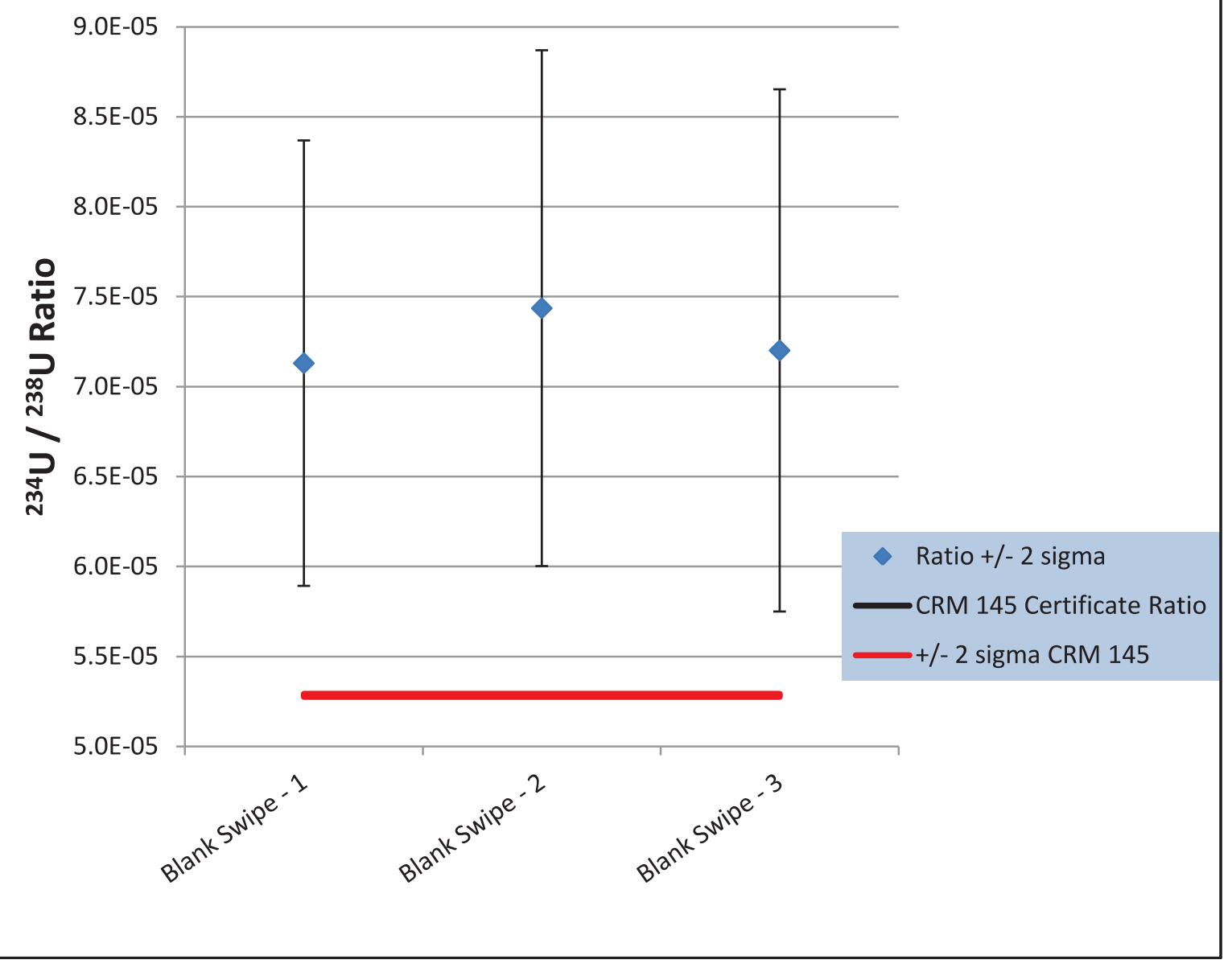

Figure 5. Measured ${ }^{234} \mathrm{U} /{ }^{238} \mathrm{U}$ ratios of clean swipes processed through the chemistry along with 3.3 pg of CRM 111A for quantification and measured by ICPMS. Data show +/- 2 sigma with the natural standard CRM 145 certified value shown on the bold black line and the uncertainty at 2 sigma is plotted in red.

\section{Blank Reagents}

Figures 6 and 7 present the measured isotope ratios for ${ }^{235} \mathrm{U} /{ }^{238} \mathrm{U}$ and ${ }^{234} \mathrm{U} /{ }^{238} \mathrm{U}$ from the reagents used in the process. The ${ }^{235} \mathrm{U} /{ }^{238} \mathrm{U}$ ratio, within the uncertainty bands, corresponds to natural abundance. The ${ }^{234} \mathrm{U} /{ }^{238} \mathrm{U}$ may be slightly enriched in ${ }^{234} \mathrm{U}$; however, the large uncertainty band, due to the low level of $U$ in the sample, overlaps the normal ratio. ${ }^{236} \mathrm{U}$ was not detected in these samples. 


\section{Reagent Blanks}

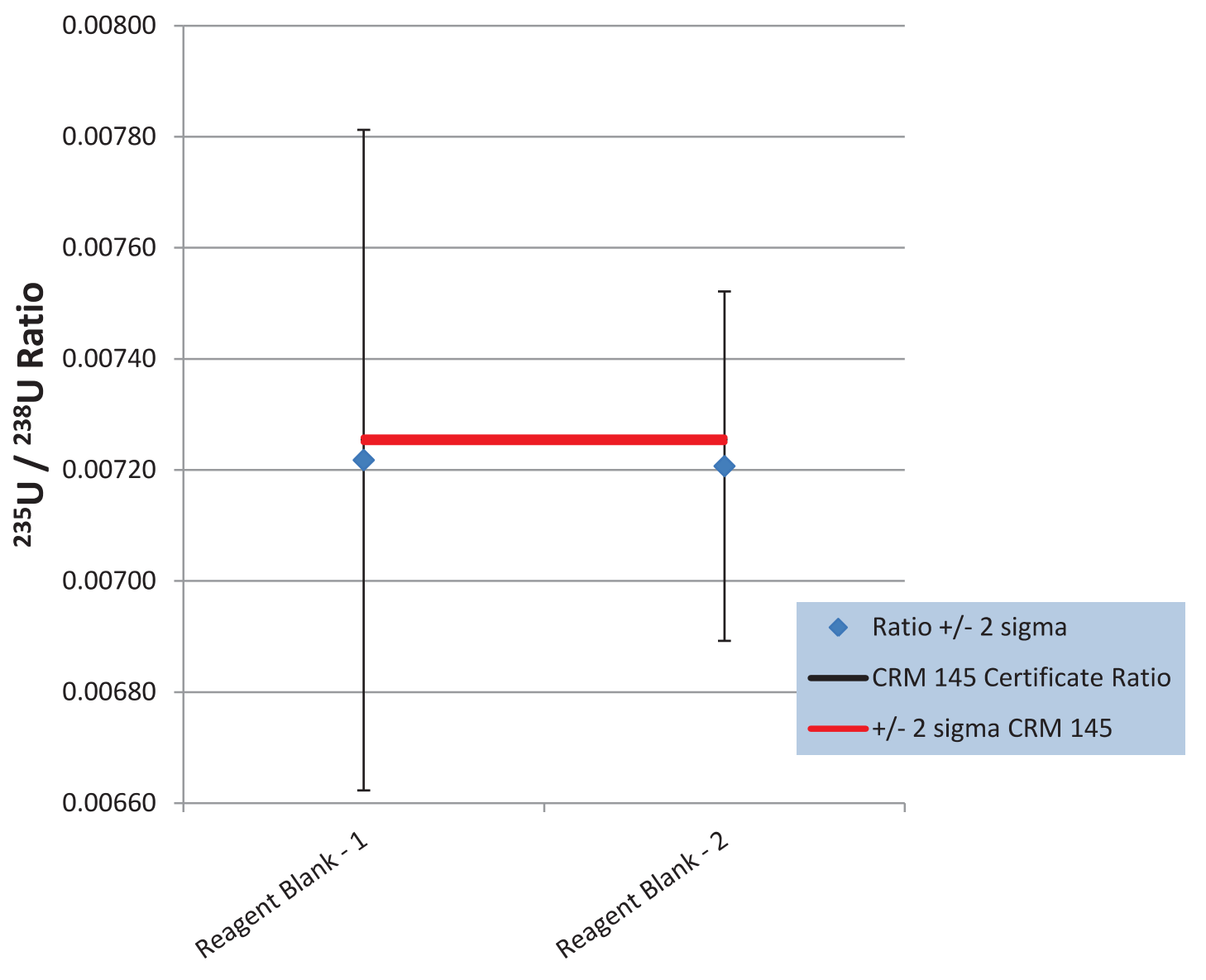

Figure 6. Measured ${ }^{235} \mathrm{U}{ }^{238} \mathrm{U}$ ratios of the reagents used in the dissolution, processed through the chemistry along with $3.3 \mathrm{pg}$ of CRM 111A for quantification and measured by ICPMS. Data show +/- 2 sigma with the natural standard CRM 145 certified value shown on the bold black line and the uncertainty at 2 sigma is plotted in red. 


\section{Reagent Blanks}

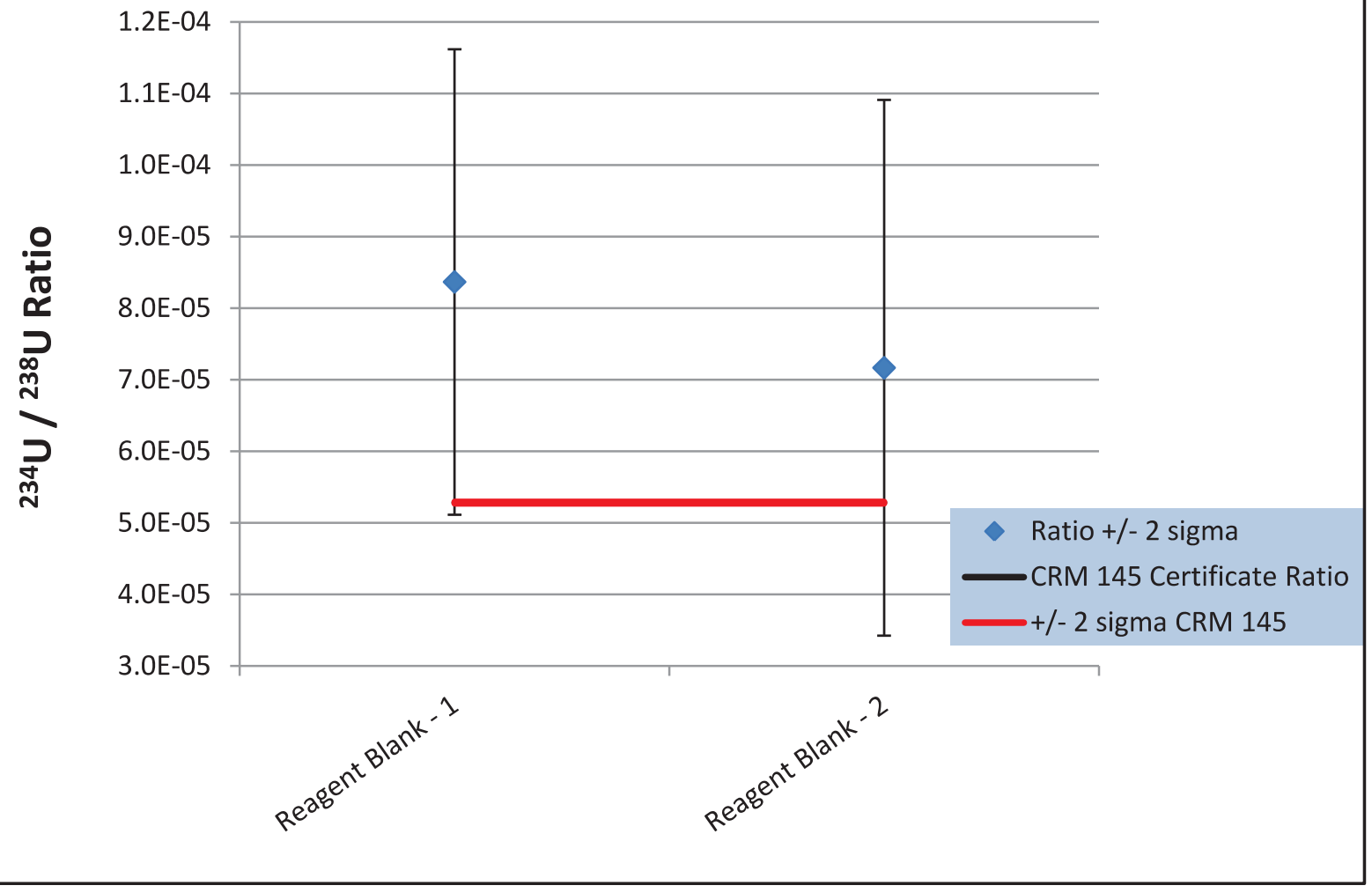

Figure 7. Measured ${ }^{234} \mathrm{U} /{ }^{238} \mathrm{U}$ ratios of reagents used in the dissolution, processed through the chemistry along with $3.3 \mathrm{pg}$ of CRM 111A for quantification and measured by ICPMS. Data show +/- 2 sigma with the natural standard CRM 145 certified value shown on the bold black line and the uncertainty at 2 sigma is plotted in red.

\section{Swipes spiked with Standards}

Figures 8 and 9 present the measured isotope ratios for ${ }^{235} \mathrm{U} /{ }^{238} \mathrm{U}$ and ${ }^{234} \mathrm{U} /{ }^{238} \mathrm{U}$ from the swipes spiked with the CRM 145 standard and processed with the described method. The ${ }^{235} \mathrm{U} /{ }^{238} \mathrm{U}$ ratio is at the natural abundance value. The ${ }^{234} \mathrm{U} /{ }^{238} \mathrm{U}$ ratio is enriched in ${ }^{234} \mathrm{U}$, consistent with the results seen from the blank swipe. The expected ${ }^{234} \mathrm{U} /{ }^{238} \mathrm{U}$ ratio from a mixture of $2.4 \mathrm{ng}$ of $\mathrm{U}$ with the average isotopic content of the blank swipes and $22 \mathrm{ng}$ of CRM 145 would be $5.48 \times 10^{-5}$. The average of five measurements for this mixture was $5.45 \times 10^{-5}$, only $0.5 \%$ different from the expected. ${ }^{236} \mathrm{U}$ was not detected in these samples. 


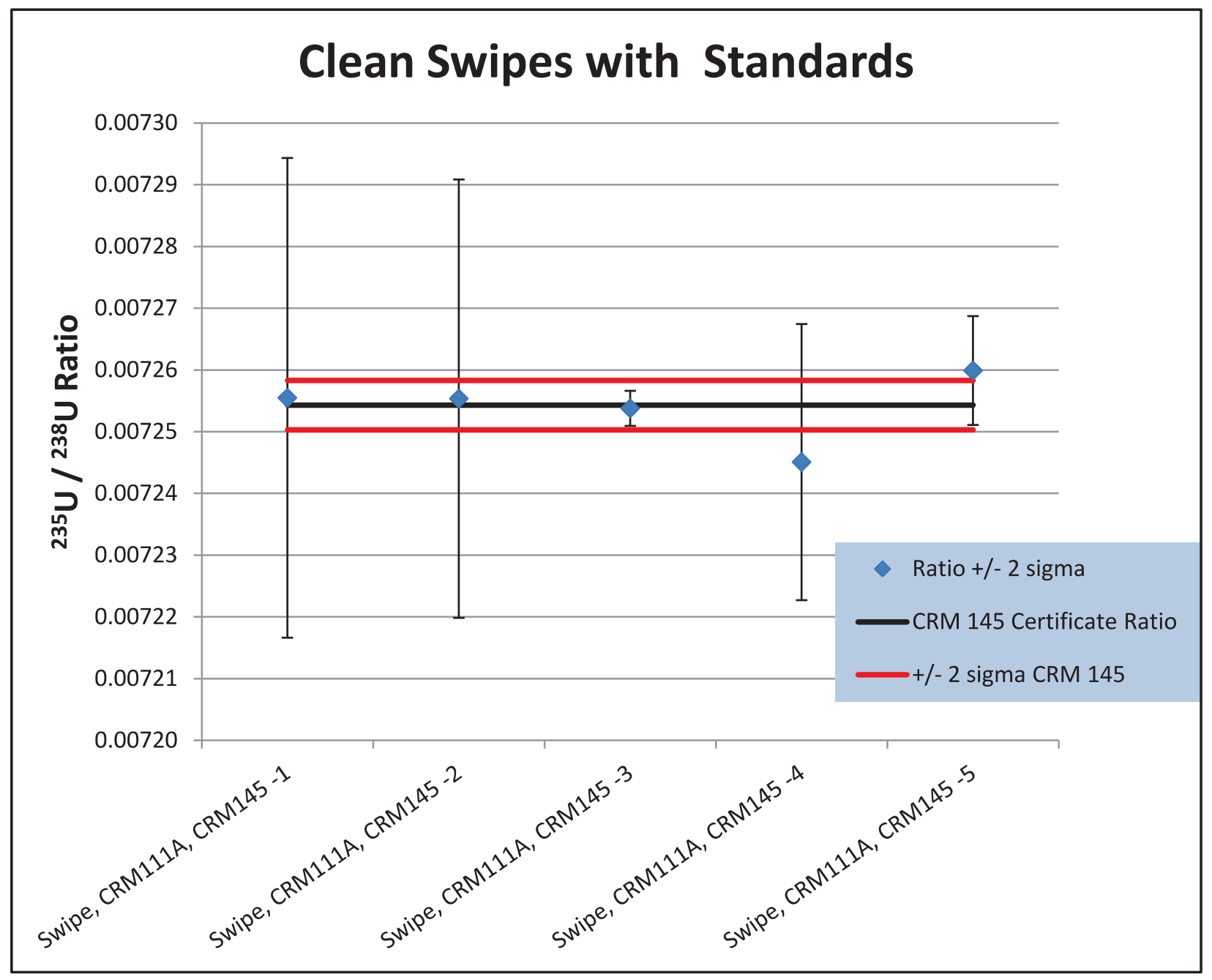

Figure 8. Measured ${ }^{235} \mathrm{U} /{ }^{238} \mathrm{U}$ ratios of clean swipes spiked with $22 \mathrm{ng}$ of CRM 145 and processed through the chemistry along with $3.3 \mathrm{pg}$ of CRM 111A for quantification and measured by ICPMS. Data show +/- 2 sigma with the natural standard CRM 145 certified value shown on the bold black line and the uncertainty at 2 sigma is plotted in red. 


\section{Clean Swipes with Standards}

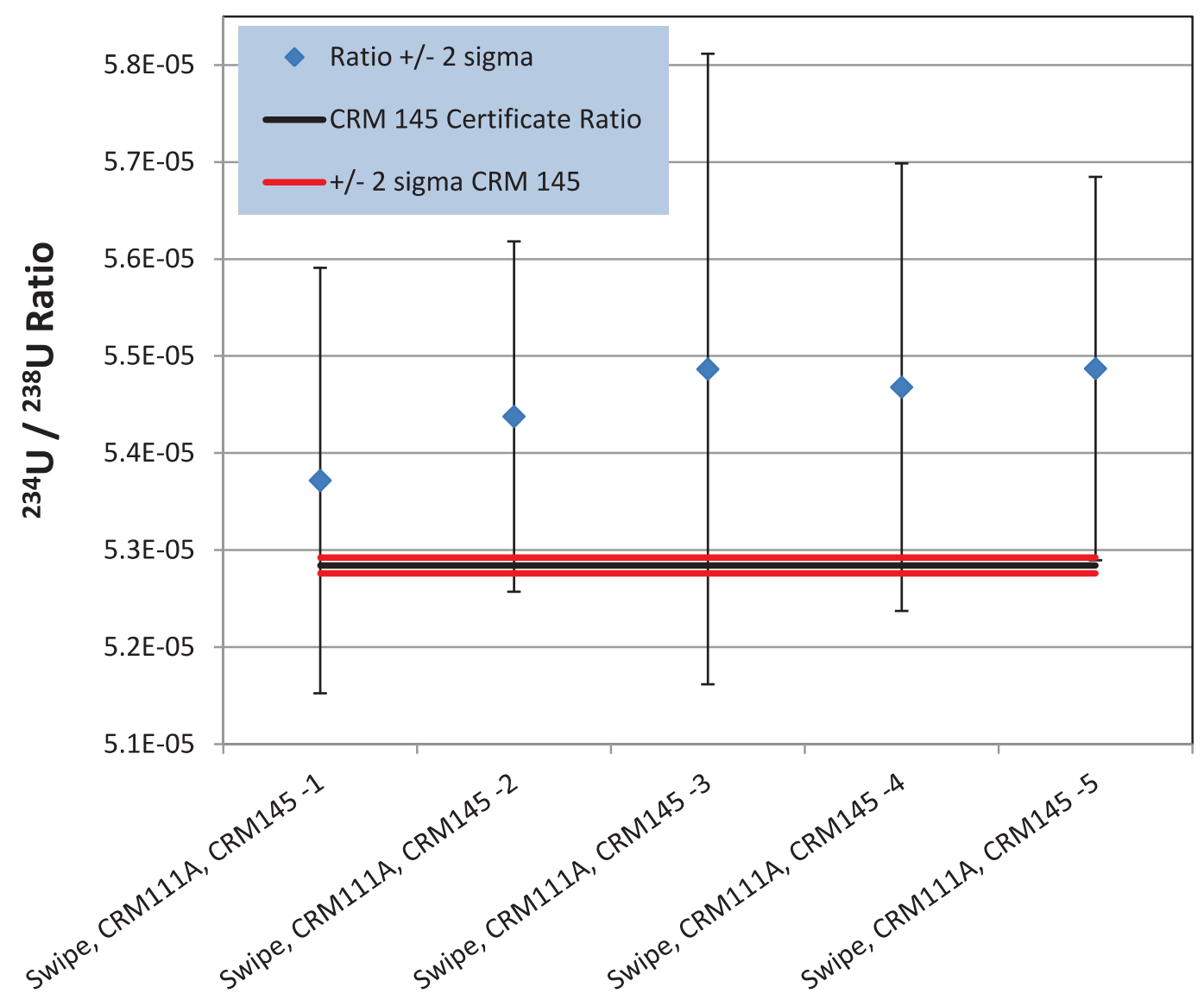

Figure 9. Measured ${ }^{234} \mathrm{U} /{ }^{238} \mathrm{U}$ ratios of clean swipes spiked with $22 \mathrm{ng}$ of CRM 145 and processed through the chemistry along with $3.3 \mathrm{pg}$ of CRM 111A for quantification and measured by ICPMS. Data show +/- 2 sigma with the natural standard CRM 145 certified value shown on the bold black line and the uncertainty at 2 sigma is plotted in red.

Figure 10 and 11 present the measured isotope ratios for ${ }^{235} \mathrm{U} /{ }^{238} \mathrm{U}$ and ${ }^{234} \mathrm{U} /{ }^{238} \mathrm{U}$ from the swipes spiked with the 4350B standard and processed with the described method. The measured ${ }^{235} \mathrm{U} /{ }^{238} \mathrm{U}$ ratio is at the natural abundance value of the standard. The measured ${ }^{234} \mathrm{U} /{ }^{238} \mathrm{U}$ ratio of $5.92 \mathrm{E}-5$ is enriched in ${ }^{234} \mathrm{U}$ compared to natural $(5.46 \mathrm{E}-5)$, but this is consistent with a published measurement of $5.82 \mathrm{E}-5$ for the ${ }^{234} \mathrm{U} /{ }^{238} \mathrm{U}$ ratio for this standard. This is a clear demonstration that the method can accurately detect a perturbation in the ${ }^{234} \mathrm{U} /{ }^{238} \mathrm{U}$ isotope ratio at a level of $\sim 20 \mathrm{ng}$ total uranium in the sample. ${ }^{236} \mathrm{U}$ was not detected in these samples. 


\section{B Analysis}

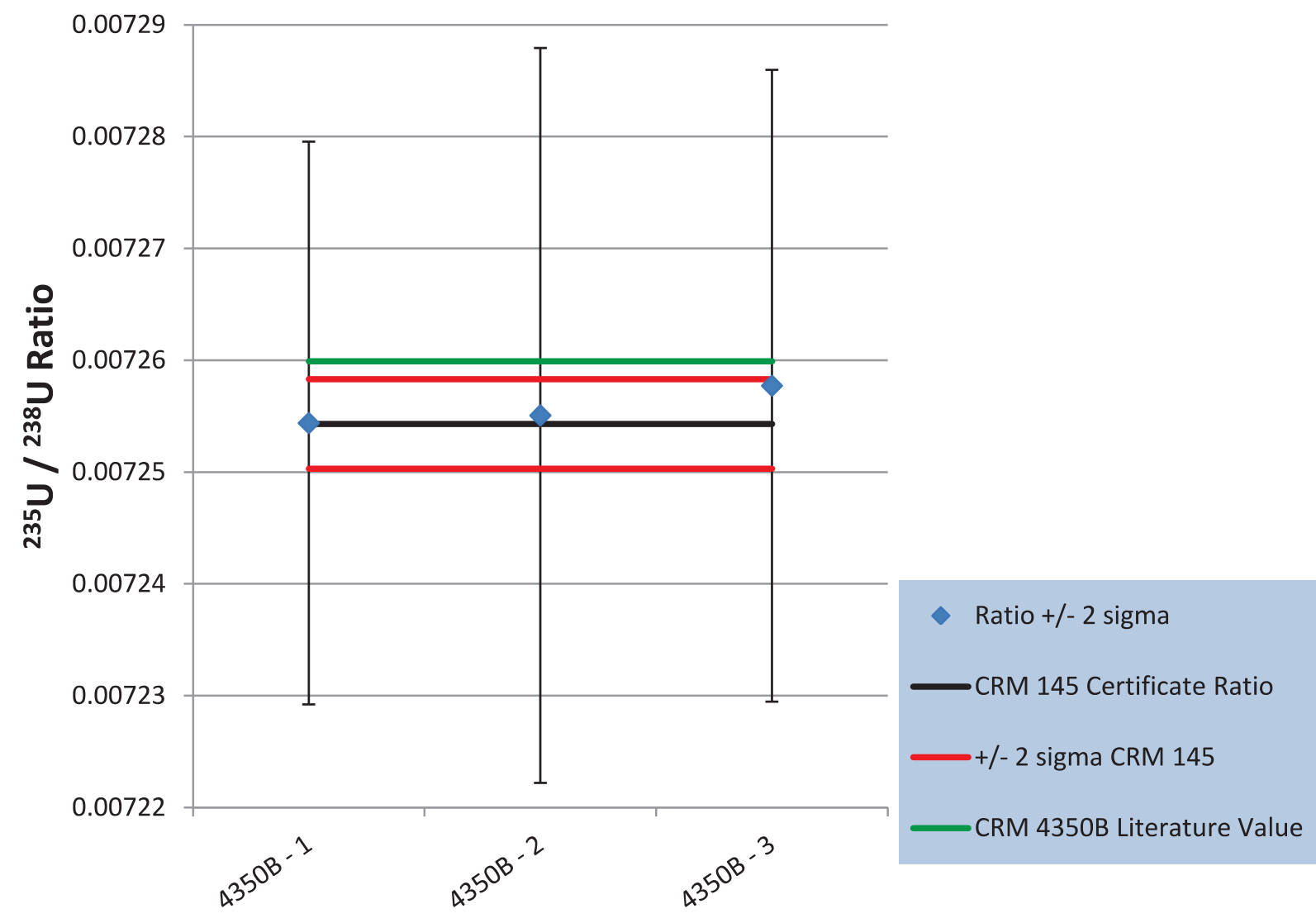

Figure 10. Measured ${ }^{235} \mathrm{U} /{ }^{238} \mathrm{U}$ ratios of clean swipes spiked with $4350 \mathrm{~B}$ and processed through the chemistry along with $3.3 \mathrm{pg}$ of CRM 111A for quantification and measured by ICPMS. Data show +/- 2 sigma with the natural standard CRM 145 certified value shown on the bold black line and the uncertainty at 2 sigma is plotted in red. 


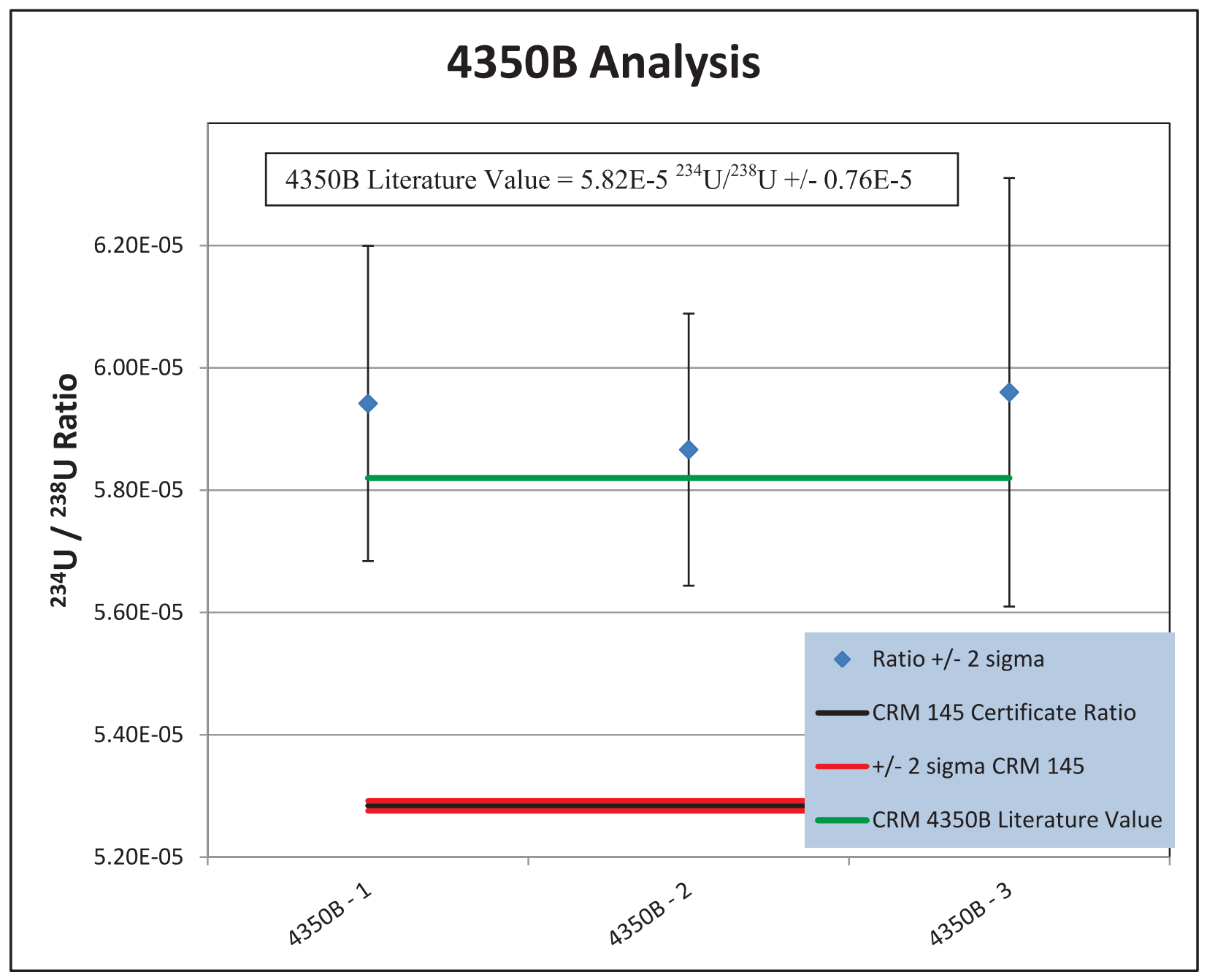

Figure 11. Measured ${ }^{234} \mathrm{U} /{ }^{238} \mathrm{U}$ ratios of clean swipes spiked with $4350 \mathrm{~B}$ and processed through the chemistry along with $3.3 \mathrm{pg}$ of CRM 111A for quantification and measured by ICPMS. Data show +/- 2 sigma with the natural standard CRM 145 certified value shown on the bold black line and the uncertainty at 2 sigma is plotted in red.

\section{Swipes of environmental samples}

A variety of surfaces within the processing laboratory and the general INL environment were sampled. The first group was used to determine the background levels of $U$ within the processing laboratory and its adjoining building, and the second group to demonstrate the viability of the methods on samples collected from an environment more typical of the anticipated application. Because of the long history of nuclear fuel development and processing at the INL it was anticipated that the isotope ratios would likely be enriched or depleted.

Figures 12 and 13 present the measured ${ }^{235} \mathrm{U} /{ }^{238} \mathrm{U}$ and ${ }^{234} \mathrm{U} /{ }^{238} \mathrm{U}$ ratios from the samples taken inside the clean room. The ratios are nearly identical to those measured for the blank swipe, the ${ }^{235} \mathrm{U} /{ }^{238} \mathrm{U}$ is at the natural level and the ${ }^{234} \mathrm{U} /{ }^{238} \mathrm{U}$ is enriched to the sample level detected for the blank swipe. Note that the total $U$ present in these samples was only $\sim 4 \mathrm{ng}$, consistent with the expected contribution from the blank swipe and 
reagents. These results demonstrate that the clean rooms provide the necessary level of cleanliness.

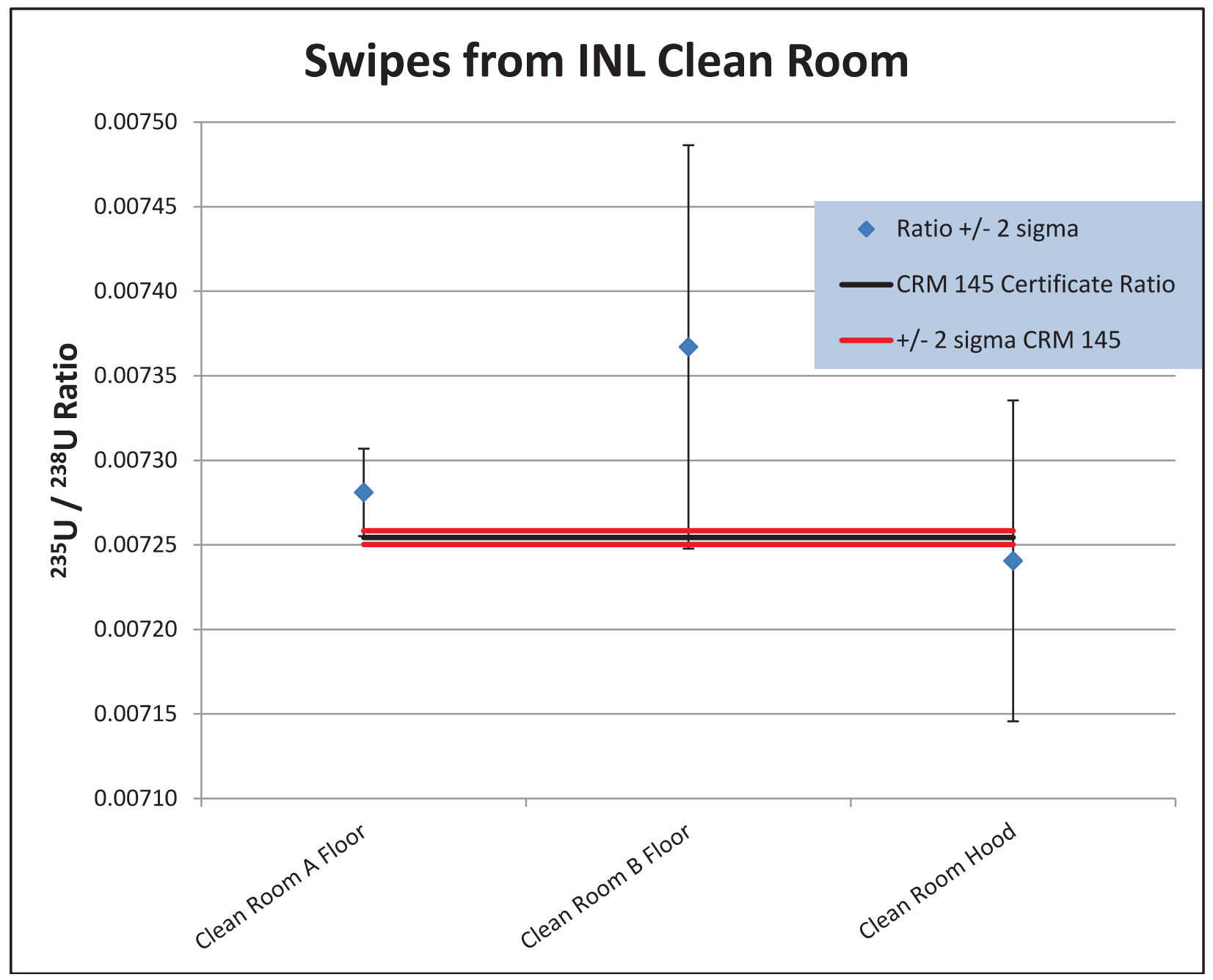

Figure 12. Measured ${ }^{235} \mathrm{U} /{ }^{238} \mathrm{U}$ ratios of swipes taken in the clean room processed through the chemistry along with $3.3 \mathrm{pg}$ of CRM 111A for quantification and measured by ICPMS. Data show +/- 2 sigma with the natural standard CRM 145 certified value shown on the bold black line and the uncertainty at 2 sigma is plotted in red. 


\section{Swipes from INL Clean Room}

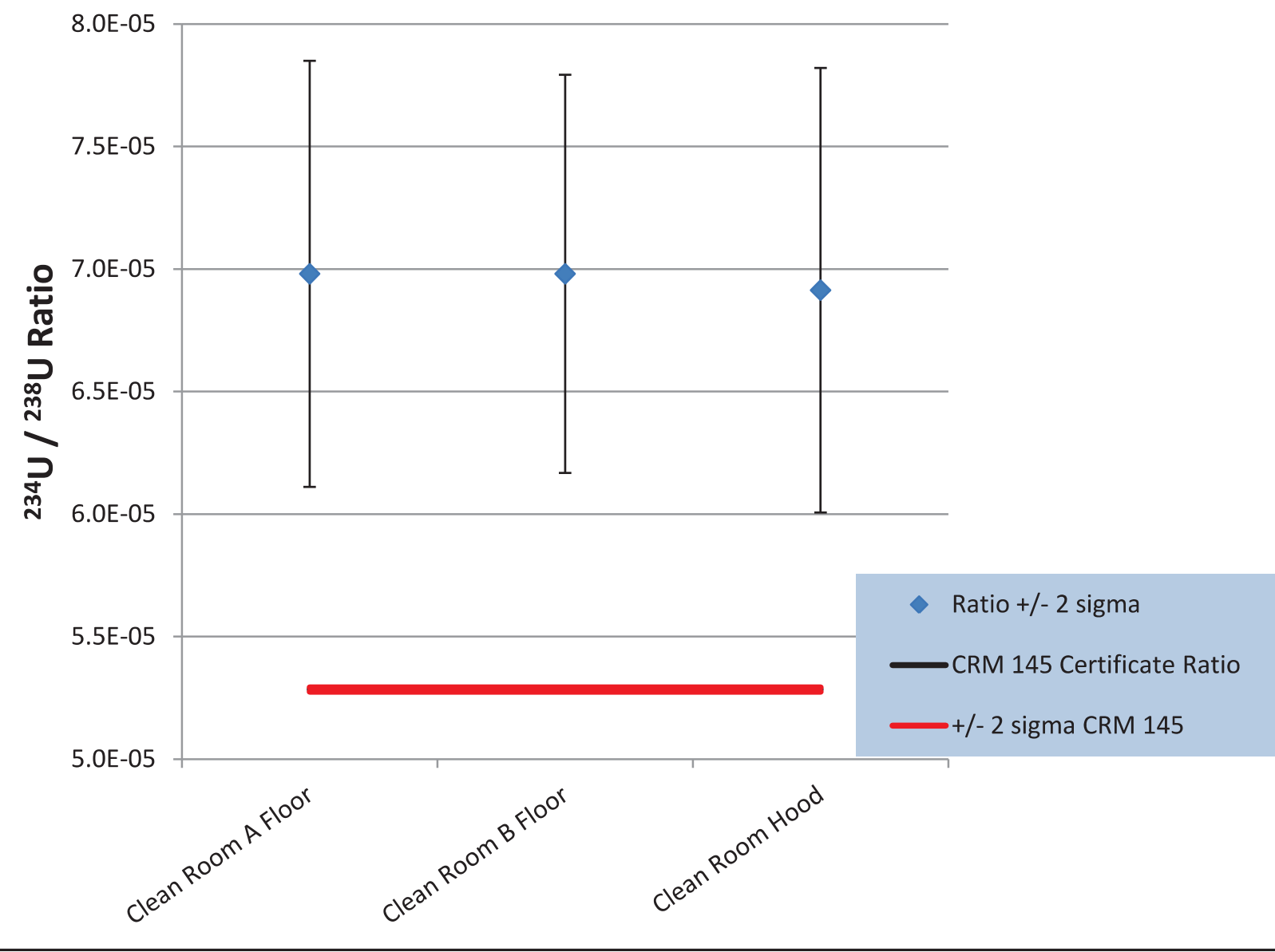

Figure 13. Measured ${ }^{234} \mathrm{U} /{ }^{238} \mathrm{U}$ ratios of swipes taken in the clean room processed through the chemistry along with $3.3 \mathrm{pg}$ of CRM 111A for quantification and measured by ICPMS. Data show +/- 2 sigma with the natural standard CRM 145 certified value shown on the bold black line and the uncertainty at 2 sigma is plotted in red.

Figures 14 and 15 present the measured ${ }^{235} \mathrm{U} /{ }^{238} \mathrm{U}$ and ${ }^{234} \mathrm{U} /{ }^{238} \mathrm{U}$ ratios for samples collected around the laboratory facility where the samples are processed. The samples were from two laboratories that were recently remodeled, from the common hallway for the building, from outside the building, and from the laboratory within the same building used to process gas standards. Generally the measured ${ }^{235} \mathrm{U} /{ }^{238} \mathrm{U}$ signatures were slightly depleted or natural. The sample from the 611-102 counter was the most depleted ${ }^{235} \mathrm{U} /{ }^{238} \mathrm{U}$ ratio observed and the ${ }^{234} \mathrm{U} /{ }^{238} \mathrm{U}$ ratio for this sample was the most enriched for samples from the building. This counter is in one of the remodeled laboratories. The craftsmen working on the remodel kept dedicated boots, and tools were cleaned as they entered the facility, but even with these measures it appears that some contamination was introduced. Note that no sample handling or processing takes place in these laboratories.

The last four data points show samples from inside the Gas Lab and associated office where operations have been conducted for a few years. The isotopic signatures are consistent with those seen in other parts of the building. There higher uncertainty in the 
office and hood measurements is indicative of the small amount of uranium in the sample, likely due to the areas being kept cleaner. The final data point is from the surface of a gas sphere clam shell container which has been in many different off-site facilities. The total uranium for this sample $(16 \mathrm{ng})$ is well above the blank level $(2 \mathrm{ng})$; the ${ }^{235} \mathrm{U} /{ }^{238} \mathrm{U}$ ratio signature is natural and the ${ }^{234} \mathrm{U} /{ }^{238} \mathrm{U}$ ratio is slightly enriched, typical of most of the samples.

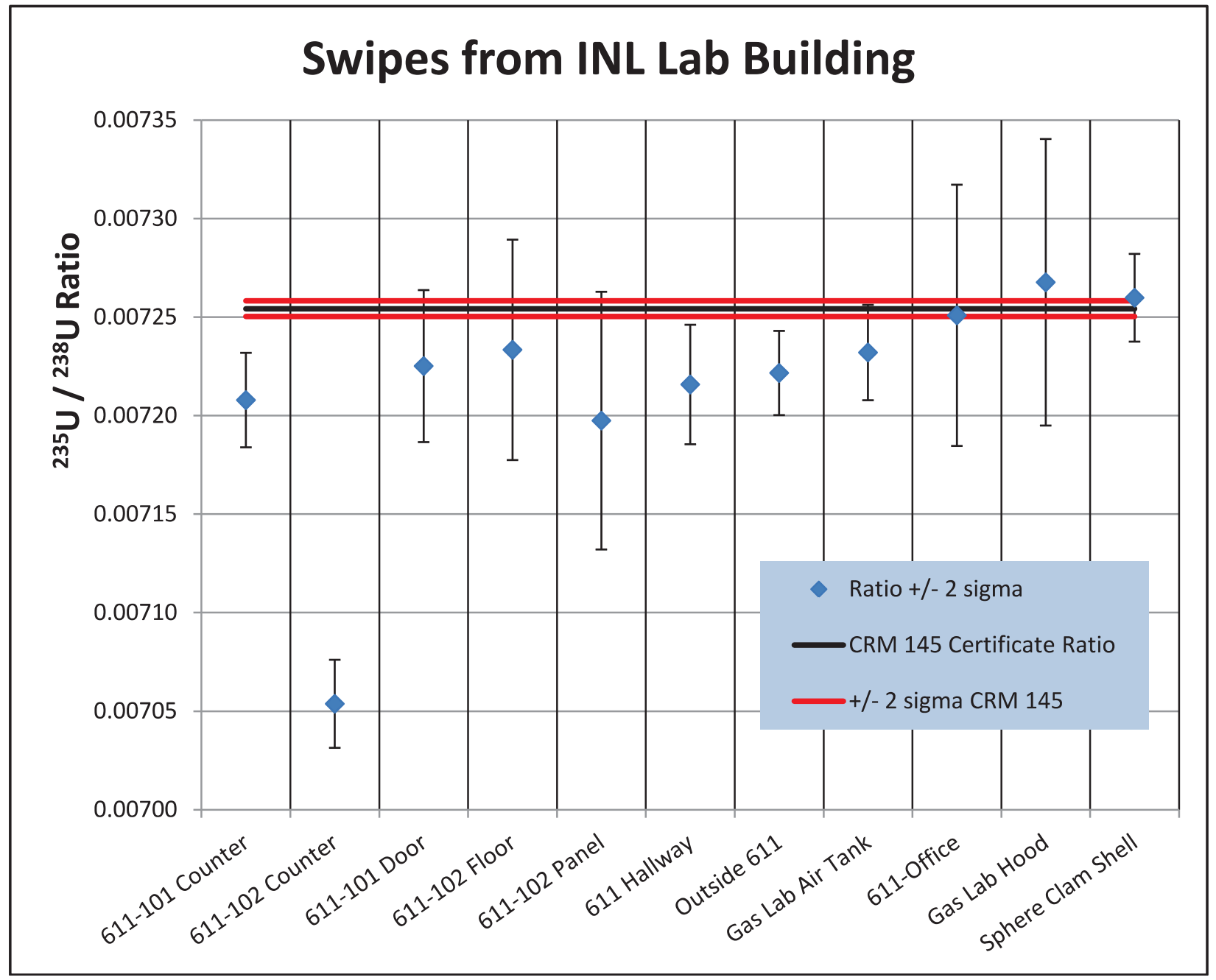

Figure 14. Measured ${ }^{235} \mathrm{U} /{ }^{238} \mathrm{U}$ ratios of swipes taken around INL building IF-611 processed through the chemistry along with $3.3 \mathrm{pg}$ of CRM $111 \mathrm{~A}$ for quantification and measured by ICPMS. Data show +/- 2 sigma with the natural standard CRM 145 certified value shown on the bold black line and the uncertainty at $\mathbf{2}$ sigma is plotted in red. 


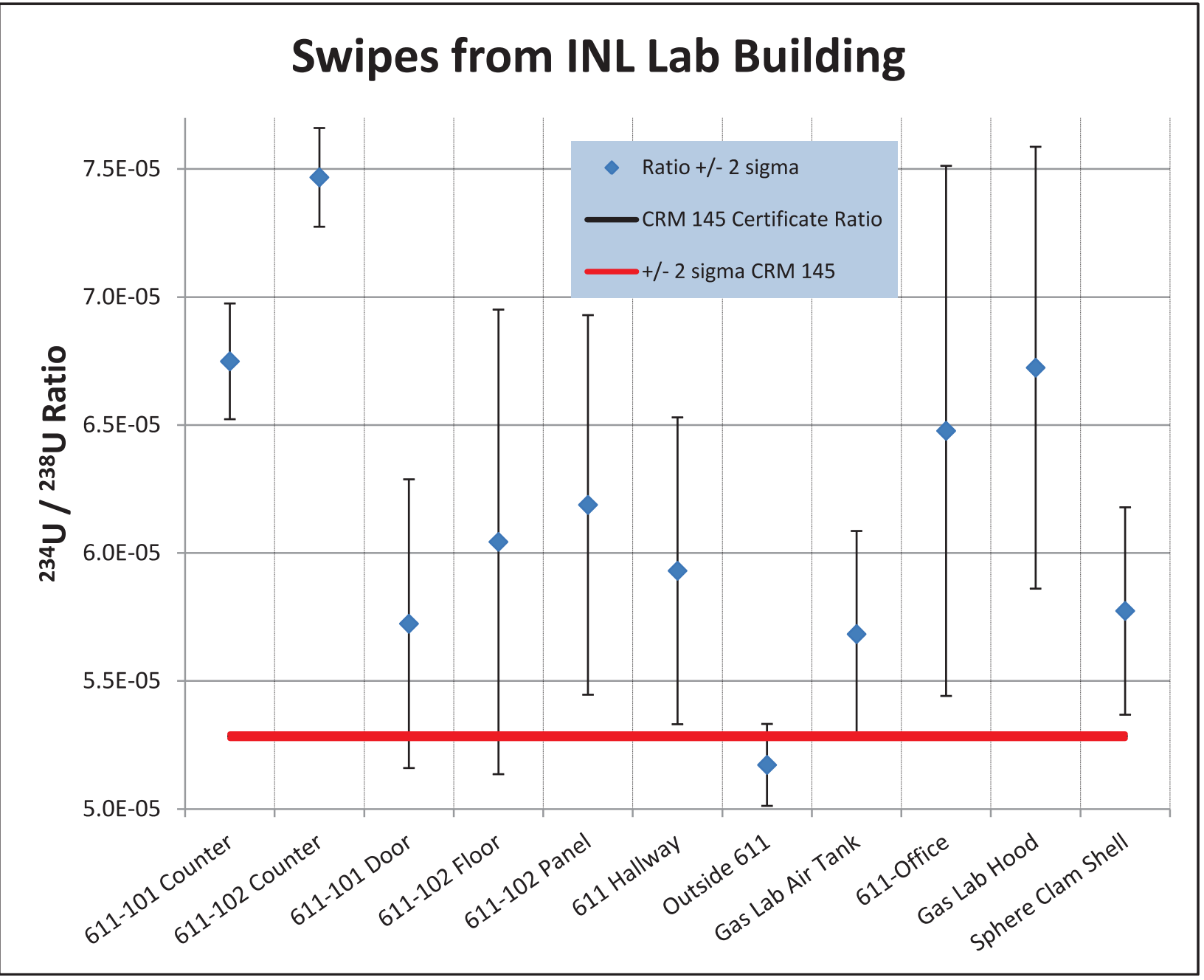

Figure 15. Measured ${ }^{234} \mathrm{U} /{ }^{238} \mathrm{U}$ ratios of swipes taken around INL building IF-611 processed through the chemistry along with $3.3 \mathrm{pg}$ of CRM 111A for quantification and measured by ICPMS. Data show +/- 2 sigma with the natural standard CRM 145 certified value shown on the bold black line and the uncertainty at $\mathbf{2}$ sigma is plotted in red.

Figures 16 and 17 present the measured ${ }^{235} \mathrm{U} /{ }^{238} \mathrm{U}$ and ${ }^{234} \mathrm{U} /{ }^{238} \mathrm{U}$ ratios for samples collected from a truck that travels to the INL Materials and Fuel Complex (MFC) and other INL locations on a daily basis, and from a xenon gas cylinder that had resided at MFC for many years and was recently moved to the IRC complex. The MFC is located 50 miles west of the IRC. The sample from the truck has a natural ${ }^{235} \mathrm{U} /{ }^{238} \mathrm{U}$ ratio signature with a slightly enriched ${ }^{234} \mathrm{U} /{ }^{238} \mathrm{U}$ ratio, attributed to the contribution from the swipe.

Two samples were collected from the xenon gas cylinder, both showed an enriched ${ }^{235} \mathrm{U} /{ }^{238} \mathrm{U}$ signature and a ${ }^{234} \mathrm{U} /{ }^{238} \mathrm{U}$ signature typical of most samples. The enriched ${ }^{235} \mathrm{U} /{ }^{238} \mathrm{U}$ signature is reasonable given the legacy and ongoing fuel manufacturing, processing and examinations that occur at the MFC complex. These samples also included a signal at 236 , which could be attributed to ${ }^{236} \mathrm{U}$ as discussed below. 


\section{Swipes from INL Materials and Fuels Complex}

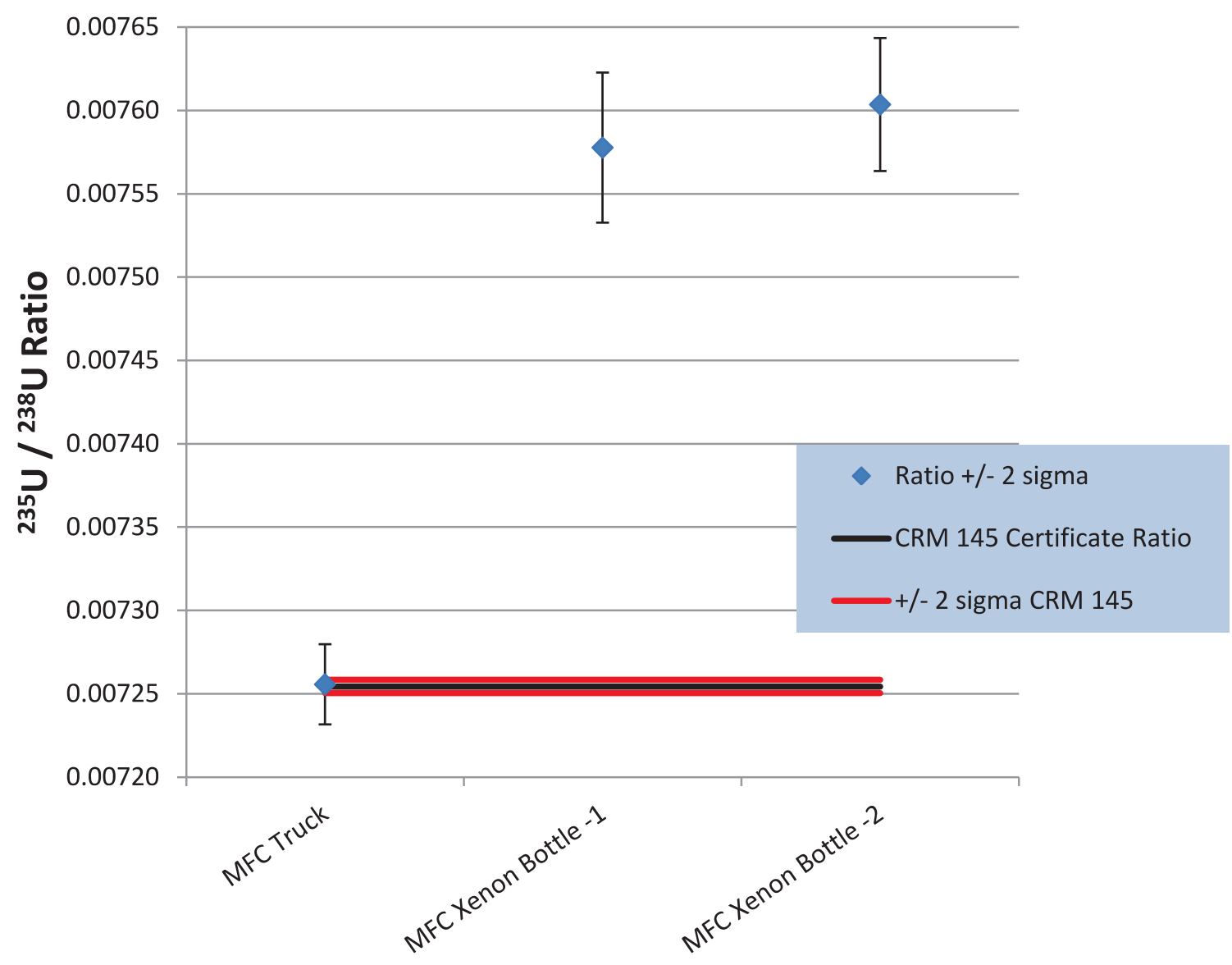

Figure 16. Measured ${ }^{235} \mathrm{U} /{ }^{238} \mathrm{U}$ ratios of swipes taken on a truck side panel and a xenon gas cylinder (twice), processed through the chemistry along with $3.3 \mathrm{pg}$ of CRM 111A for quantification and measured by ICPMS. Data show +/- 2 sigma with the natural standard CRM 145 certified value shown on the bold black line and the uncertainty at 2 sigma is plotted in red. 


\section{Swipes from INL Materials and Fuels Complex}

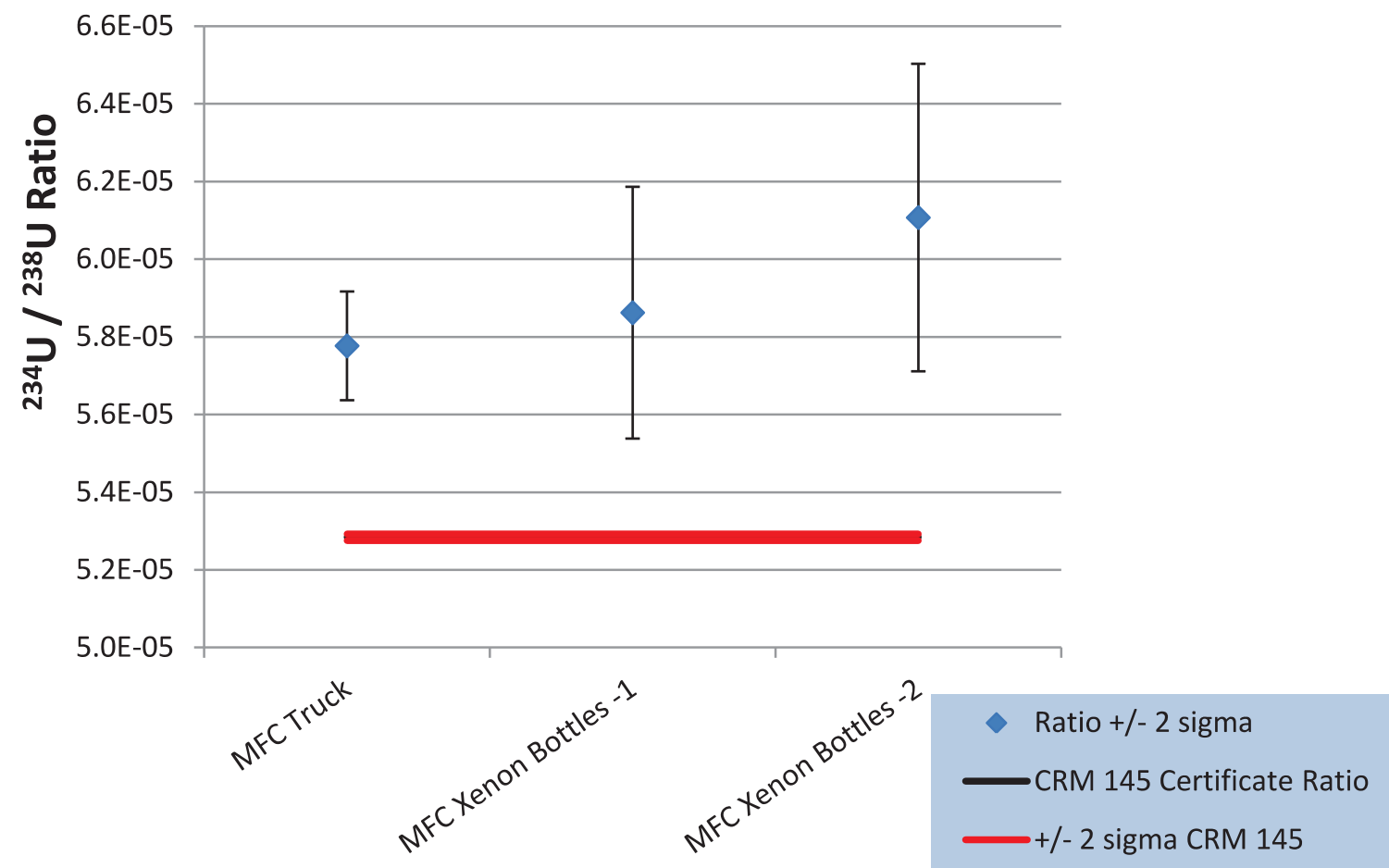

Figure 17. Measured ${ }^{234} \mathrm{U} /{ }^{238} \mathrm{U}$ ratios of swipes taken on a truck side panel and a xenon gas cylinder (twice), processed through the chemistry along with $3.3 \mathrm{pg}$ of CRM 111A for quantification and measured by ICPMS. Data show +/- 2 sigma with the natural standard CRM 145 certified value shown on the bold black line and the uncertainty at 2 sigma is plotted in red.

\section{Detection of $236 U$}

After accounting for peak tailing from ${ }^{235} \mathrm{U}$ and ${ }^{238} \mathrm{U}$ the LOD for ${ }^{236} \mathrm{U}$ was determined to be 9 million atoms (3.4 fg) and the LOQ 29 million atoms (11.4 fg). A signal above the LOD at mass 236 was detected on 6 of the samples. Two of these were at levels below the LOQ (611-101 counter and 611-101 door). The other four were found on swipes of the xenon gas bottle, the 611-102 counter, and the Clean Room A floor. The natural abundance of ${ }^{236} \mathrm{U}$ is $<1 \times 10^{-11}$ and thus is typically not detected in natural samples. However, it is a major component of uranium exposed to a neutron flux and thus a major component of reprocessed or spent nuclear fuel and thus becomes a signature for reactor operation or fuel reprocessing. Nuclear research and operations at the INL during its history make it highly likely that uranium samples from the main complexes (such as MFC) will contain ${ }^{236} \mathrm{U}$. The origins of the samples in this study in which a 236 signal was detected all have a link to the MFC complex. The xenon bottle spent years at the MFC and was not cleaned before being relocated to the IRC complex, thus it was not surprising to find a 236 signal in those two samples. The 611-101/2 counters and the 611-101 door were all in areas in which crafts personnel had recently spent considerable time remodeling. The crafts personnel perform tasks both at MFC and at the IRC, and their tools and equipment are used in both locations. While efforts were made to reduce the chance that contamination from MFC would be transferred to the IRC 611 building, it seems likely that this did occur. The clean room is located inside IRC 611 which has a 
common hallway where personnel routinely move from one end of the hall to the next. This is the suspected route for the 236 contamination seen on the sample from Clean Room A floor. The clean rooms and all associated areas have since been cleaned but not yet re-sampled.

\section{Data Summary}

Table 1 presents all of the measured isotope ratios and the 2 sigma uncertainty for the samples discussed in this report. Where the minor isotope was below the LOD a ratio is not reported. Table 2 presents the quantity of each isotope measured above the LOD for all of the samples. 


\begin{tabular}{|c|c|c|c|c|c|c|}
\hline & ${ }^{234} U /{ }^{238} U$ & $\begin{array}{c}{ }^{234} \mathrm{U} /{ }^{238} \mathrm{U} \text { std } \\
\text { dev of } \\
\text { measurement }\end{array}$ & ${ }^{235} U /{ }^{238} U$ & $\begin{array}{c}{ }^{235} \mathrm{U} /{ }^{238} \mathrm{U} \text { std } \\
\text { dev of } \\
\text { measurement }\end{array}$ & $\begin{array}{l}{ }^{236} \mathrm{U} /{ }^{238} \mathrm{U} \\
\text { Corrected }\end{array}$ & $\begin{array}{c}{ }^{236} \mathrm{U} /{ }^{238} \mathrm{U} \text { std } \\
\text { dev of } \\
\text { measurement }\end{array}$ \\
\hline Swipe, CRM111A, CRM 145 - 1 & 5.37E-05 & $2.19 \mathrm{E}-06$ & 0.007255 & 0.000039 & ND & - \\
\hline Swipe, CRM111A, CRM 145 - 2 & 5.44E-05 & $1.81 E-06$ & 0.007255 & 0.000036 & ND & - \\
\hline Swipe, CRM111A, CRM 145 - 3 & 5.49E-05 & $3.25 \mathrm{E}-06$ & 0.007254 & 0.000003 & ND & - \\
\hline Swipe, CRM111A, CRM 145 - 4 & 5.47E-05 & $2.31 \mathrm{E}-06$ & 0.007245 & 0.000022 & ND & - \\
\hline Swipe, CRM111A, CRM 145 - 5 & $5.49 \mathrm{E}-05$ & $1.98 \mathrm{E}-06$ & 0.007260 & 0.000009 & ND & - \\
\hline CRM111A, CRM 145 - 1 & 5.29E-05 & 2.04E-06 & 0.007249 & 0.000022 & ND & - \\
\hline CRM111A, CRM 145 - 2 & 5.32E-05 & $2.81 \mathrm{E}-06$ & 0.007250 & 0.000023 & ND & - \\
\hline CRM111A, CRM 145 - 3 & 5.27E-05 & $3.72 \mathrm{E}-06$ & 0.007250 & 0.000027 & ND & - \\
\hline CRM111A, CRM 145 - 4 & 5.33E-05 & $3.45 E-06$ & 0.007252 & 0.000045 & ND & - \\
\hline CRM111A, CRM 145 - 5 & $5.29 \mathrm{E}-05$ & 3.87E-06 & 0.007248 & 0.000038 & ND & - \\
\hline 4350B - 1 & 5.94E-05 & $2.58 \mathrm{E}-06$ & 0.007254 & 0.000025 & ND & - \\
\hline $4350 B-2$ & 5.87E-05 & $2.22 \mathrm{E}-06$ & 0.007255 & 0.000033 & ND & - \\
\hline $4350 B-3$ & $5.96 \mathrm{E}-05$ & $3.50 \mathrm{E}-06$ & 0.007258 & 0.000028 & ND & - \\
\hline Swipe Blank - 1 & 7.13E-05 & $1.24 \mathrm{E}-05$ & 0.007205 & 0.000129 & ND & - \\
\hline Swipe Blank - 2 & 7.44E-05 & $1.43 \mathrm{E}-05$ & 0.007256 & 0.000112 & ND & - \\
\hline Swipe Blank - 3 & $7.20 \mathrm{E}-05$ & $1.45 \mathrm{E}-05$ & 0.007209 & 0.000064 & ND & - \\
\hline Reagent Blank - 1 & 8.37E-05 & $3.25 \mathrm{E}-05$ & 0.007218 & 0.000595 & ND & - \\
\hline Reagent Blank - 2 & 7.17E-05 & $3.74 \mathrm{E}-05$ & 0.007207 & 0.000314 & ND & - \\
\hline 611-101 Counter & $6.75 \mathrm{E}-05$ & $2.26 \mathrm{E}-06$ & 0.007208 & 0.000024 & 2.01E-07 & $7.6 \mathrm{E}-08$ \\
\hline 611-102 Counter & 7.47E-05 & $1.93 \mathrm{E}-06$ & 0.007054 & 0.000022 & $1.29 \mathrm{E}-06$ & 2.7E-07 \\
\hline 611-101 Back Door & $5.72 \mathrm{E}-05$ & $5.64 \mathrm{E}-06$ & 0.007225 & 0.000039 & $2.40 E-07$ & $1.5 \mathrm{E}-07$ \\
\hline 611-102 Floor & $6.04 \mathrm{E}-05$ & $9.08 \mathrm{E}-06$ & 0.007233 & 0.000056 & ND & - \\
\hline 611-102 Electrical Panel & $6.19 \mathrm{E}-05$ & $7.41 \mathrm{E}-06$ & 0.007197 & 0.000065 & ND & - \\
\hline 611 - Hallway & 5.93E-05 & 5.99E-06 & 0.007216 & 0.000030 & ND & - \\
\hline Outside 611 & 5.17E-05 & $1.60 \mathrm{E}-06$ & 0.007222 & 0.000021 & ND & - \\
\hline Gas Lab Air Tank & $5.68 \mathrm{E}-05$ & 4.03E-06 & 0.007232 & 0.000024 & ND & - \\
\hline 611-Office & $6.48 \mathrm{E}-05$ & $1.04 \mathrm{E}-05$ & 0.007251 & 0.000066 & ND & - \\
\hline Gas Lab Hood & 6.72E-05 & 8.63E-06 & 0.007268 & 0.000073 & ND & - \\
\hline Sphere Clam Shell & 5.77E-05 & 4.05E-06 & 0.007260 & 0.000022 & ND & - \\
\hline MFC Truck & $5.78 \mathrm{E}-05$ & $1.40 \mathrm{E}-06$ & 0.007256 & 0.000024 & ND & - \\
\hline MFC Xenon Bottles - 1 & $5.86 \mathrm{E}-05$ & $3.24 \mathrm{E}-06$ & 0.007578 & 0.000045 & 2.83E-06 & $3.4 \mathrm{E}-07$ \\
\hline MFC Xenon Bottles - 2 & $6.11 \mathrm{E}-05$ & $3.96 \mathrm{E}-06$ & 0.007604 & 0.000040 & $6.88 \mathrm{E}-06$ & $4.8 \mathrm{E}-07$ \\
\hline Clean Room A Floor & $6.98 \mathrm{E}-05$ & 8.69E-06 & 0.007281 & 0.000026 & $2.25 E-06$ & $6.1 \mathrm{E}-07$ \\
\hline Clean Room B Floor & 7.74E-05 & $8.12 \mathrm{E}-06$ & 0.007367 & 0.000119 & ND & - \\
\hline Clean Room Hood & 6.91E-05 & 9.07E-06 & 0.007241 & 0.000095 & ND & - \\
\hline
\end{tabular}

Table 1. Uranium isotopic ratios expressed with the standard deviation of the measurement (2-sigma). 


\begin{tabular}{|c|c|c|c|c|}
\hline & ${ }^{234} U(p g)$ & ${ }^{235} \mathrm{U}(\mathrm{pg})$ & ${ }^{236} \mathrm{U}(\mathrm{fg})$ & ${ }^{238} \mathrm{U}(\mathrm{ng})$ \\
\hline Swipe, CRM111A, CRM 145 - 1 & 1.3 & 177 & ND & 24 \\
\hline Swipe, CRM111A, CRM 145 - 2 & 1.3 & 175 & ND & 24 \\
\hline Swipe, CRM111A, CRM 145 - 3 & 1.3 & 176 & ND & 24 \\
\hline Swipe, CRM111A, CRM 145 - 4 & 1.3 & 176 & ND & 24 \\
\hline Swipe, CRM111A, CRM 145 - 5 & 1.3 & 176 & ND & 24 \\
\hline CRM111A, CRM 145 - 1 & 1.2 & 161 & ND & 22 \\
\hline CRM111A, CRM 145 - 2 & 1.2 & 159 & ND & 22 \\
\hline CRM111A, CRM 145 - 3 & 1.2 & 160 & ND & 22 \\
\hline CRM111A, CRM 145 - 4 & 1.2 & 162 & ND & 22 \\
\hline CRM111A, CRM 145 - 5 & 1.2 & 161 & ND & 22 \\
\hline $4350 B-1$ & 2.2 & 271 & ND & 37 \\
\hline $4350 \mathrm{~B}-2$ & 2.3 & 283 & ND & 39 \\
\hline $4350 B-3$ & 2.4 & 289 & ND & 40 \\
\hline Swipe Blank - 1 & 0.17 & 17 & ND & 2.4 \\
\hline Swipe Blank - 2 & 0.16 & 15 & ND & 2.1 \\
\hline Swipe Blank - 3 & 0.17 & 17 & ND & 2.3 \\
\hline Reagent Blank - 1 & 0.02 & 1.9 & ND & 0.3 \\
\hline Reagent Blank - 2 & 0.02 & 2.2 & ND & 0.3 \\
\hline 611-101 Counter & 3.6 & 388 & 10.8 & 54 \\
\hline 611-102 Counter & 1.8 & 174 & 31.8 & 25 \\
\hline 611-101 Back Door & 1.2 & 147 & 4.9 & 20 \\
\hline 611-102 Floor & 0.53 & 64 & ND & 8.8 \\
\hline 611-102 Electrical Panel & 0.37 & 43 & ND & 5.9 \\
\hline 611 - Hallway & 0.80 & 98 & ND & 14 \\
\hline Outside 611 & 5.9 & 825 & ND & 114 \\
\hline Gas Lab Air Tank & 1.0 & 133 & ND & 18 \\
\hline 611-Office & 0.34 & 38 & ND & 5.2 \\
\hline Gas Lab Hood & 0.38 & 41 & ND & 5.6 \\
\hline Sphere Clam Shell & 0.95 & 119 & ND & 16 \\
\hline MFC Truck & 1.9 & 241 & ND & 33 \\
\hline MFC Xenon Bottles - 1 & 1.2 & 154 & 57 & 20 \\
\hline MFC Xenon Bottles - 2 & 1.2 & 149 & 134 & 20 \\
\hline Clean Room A Floor & 0.43 & 45 & 13.8 & 6.1 \\
\hline Clean Room B Floor & 0.19 & 18 & ND & 2.4 \\
\hline Clean Room Hood & 0.28 & 29 & ND & 4.0 \\
\hline
\end{tabular}

Table 2. Mass content by isotope for uranium.

\section{Statistical test of difference}

To systematically determine if a measured isotope ratio differs from the natural ratio a test (of hypothesis) for a significant difference between a measured value and the 
certified standard value was applied as follows. The certified ${ }^{235} \mathrm{U} /{ }^{238} \mathrm{U}$ atom ratio for CRM-145 is 0.0072543 , with an uncertainty at the $95 \%$ confidence level (two standard deviations) of 0.000004 . Multiple measurements of CRM-145 on the ICPMS result in an estimated processed sample uncertainty (two standard deviations) of $2 \hat{\sigma}$. With approximate $95 \%$ confidence, a measured ${ }^{235} \mathrm{U} /{ }^{238} \mathrm{U}$ atom ratio, denoted by $Y$, will significantly differ from the certified ${ }^{235} \mathrm{U} /{ }^{238} \mathrm{U}$ atom ratio (thereby indicating non-natural uranium in the sample), if

Equation 3. $\quad|Y-0.0072543|>2 \sqrt{\hat{\sigma}^{2}+0.000002^{2}}$

where

$$
\begin{aligned}
& \mathrm{Y}={ }^{235} \mathrm{U} /{ }^{238} \mathrm{U} \text { measured } \\
& \sigma=\quad \text { the processed sample uncertainty determined by using the } \\
& \text { standard deviation of the results from the most recent } 20 \\
& \text { blank filters spiked with CRM } 145 \text { at } 20 \mathrm{ng} \text { total uranium. }
\end{aligned}
$$

Applying this test the ratio perturbation detectable by this method is $+/-1 \times 10^{-5}$ $(0.007254+/-0.000010)$ from natural for ${ }^{235} U /{ }^{238} U$. To date ten measurements have been collected and these were used to generate the sigma in applying this test to the CRM $4350 \mathrm{~B}$ results presented in Table 1 . In the future it is proposed that this test would be applied using a 20 sample moving average of $\hat{\sigma}$, the estimated processed sample uncertainty obtained via measurement of CRM-145 on the ICPMs. The 20 sample moving average will be implemented once the data set is larger than 20 . This same method was applied to the ${ }^{234} \mathrm{U} /{ }^{238} \mathrm{U}$ ratios of CRM 4350B shown in Table 1 . This test shows samples that would be considered to have natural isotopic content. Table 3 shows that the results from this test confirm the discussion above. The ${ }^{235} \mathrm{U} /{ }^{238} \mathrm{U}$ ratio is natural in $4350 \mathrm{~B}$ and the ${ }^{234} \mathrm{U} /{ }^{238} \mathrm{U}$ ratio is not natural. The literature values reported for $4350 \mathrm{~B}$ are in agreement with these findings.

\begin{tabular}{|ccc|}
\hline Sample & $\begin{array}{c}\text { Natural } \\
234\end{array} / /^{238} \mathrm{U}$ & $\begin{array}{c}\text { Natural } \\
235\end{array} / /^{238} \mathrm{U}$ \\
\hline \hline 4350B -1 & NO & YES \\
$4350 \mathrm{~B}-2$ & NO & YES \\
$4350 \mathrm{~B}-3$ & NO & YES \\
\hline
\end{tabular}

Table 3. Application of the test of difference using the Columbia River Sediment standard 4350B, which has a natural ${ }^{235} \mathrm{U} /{ }^{238} \mathrm{U}$ ratio and a non-natural ${ }^{234} \mathrm{U} /{ }^{238} \mathrm{U}$ ratio. 


\section{Conclusions and Discussion}

Advances in Inductively Coupled Plasma Mass Spectrometry over the last decade have enabled analyses of $\mathrm{U}$ and $\mathrm{Pu}$ that rival that of TIMS. This has been coupled with a simplified chemical extraction and separation process to provide the capability to quantitatively measure uranium on swipes faster and at less cost than previous methods. The measurements reported herein have clearly demonstrated that this capability provides the necessary level of detection and specificity for the uranium isotopes of interest. The minimum detectable amount of ${ }^{236} \mathrm{U}$ (LOD, defined as $3 \sigma$ ) for ${ }^{236} \mathrm{U}$ is 9 million atoms (3.4 $\mathrm{fg}{ }^{236} \mathrm{U}$ ). The limit of quantification (LOQ defined as $10 \sigma$ ) for ${ }^{236} \mathrm{U}$ is 29 million atoms $\left(11.4 \mathrm{fg}{ }^{236} \mathrm{U}\right)$. The measured limit of detection for ${ }^{238} \mathrm{U}$ from the CRM 145 spiked onto a swipe is $7.1 \times 10^{11}$ atoms of ${ }^{238} \mathrm{U}(0.28 \mathrm{ng})$ with the limit of quantification being $2.4 \times 10^{12}$ atoms of ${ }^{238} \mathrm{U}(0.93 \mathrm{ng})$. The ratio perturbation for ${ }^{235} \mathrm{U} /{ }^{238} \mathrm{U}$ detectable by this method is $+/-1 \times 10^{-5}(0.007254+/-0.000010)$ from natural. Analysis of the environmental standard 4305B (Columbia River Sediment) demonstrated the capability of the method to accurately measure the enriched ${ }^{234} \mathrm{U} /{ }^{238} \mathrm{U}$ ratio from a sample containing only $40 \mathrm{ng}$ of uranium.

The INL is confident that it is capable of quickly and efficiently detecting trace levels of uranium and plutonium present on swipe materials using methods and instrumentation that greatly reduce the cost and time of analysis. These new methods permit larger batch processing and analysis, produce less waste, and enable automated sample analysis on the mass spectrometer. In addition, for a time critical sample the new methods make it possible to turn around a sample from receipt to report of results the following day. 